\title{
PENGARUH KOMITMEN ORGANISASI, BUDAYA ORGANISASI DAN MOTIVASI TERHADAP KINERJA KARYAWAN PT. HANTAR HAMPARAN HASIL DI PASURUAN
}

\author{
As'at Rizal $^{1}$, Alshaf Pebrianggara², Achmad Ansori ${ }^{3}$
}

Program Studi Manajemen, Fakultas Ekonomi , Universitas Muhammadiyah Sidoarjo, Jl.

Majapahit, 666B, Sidoarjo, Telp (031) 8945444

Email: asatrizal@gmail.com

\begin{abstract}
Abstrak
Tujuan penelitian ini adalah untuk mengetahui Faktor - faktor yang mempengaruhi Kinerja karyawan di PT. Hantar Hamparan Hasil yang meliputi Komitmen Organisasi ( $X_{1}$ ) Budaya Organisasi $\left(X_{2}\right)$ dan Motivasi Kerja $\left(X_{3}\right)$. Penelitian ini menggunakan metode kuantitatif dengan sampel 60 orang karyawan di PT. Hantar Hamparan Hasil sebagai responden. Pengumpulan data dilakukan dengan menggunakan kuesioner. Data yang diperoleh dianalisis dengan menggunakan statistik, yakni dengan menggunakan analisis regresi berganda yang pengolahannya dilakukan dengan program SPSS versi 25.0. 1) Hasil analisis membuktikan bahwa variabel Komitmen Organisasi, Budaya Organisasi dan Motivasiberpengaruh secara simultan terhadap kinerja karyawan di PT. Hantar Hamparan Hasil. 2) Hasil analisis membuktikan bahwa Komitmen Organisasi dan Motivasiberpengaruh secara parsial terhadap Kinerja Karyawan, sedangkan Budaya Organisasi tidak berpengaruh secara parsial terhadap Kinerja Karyawan. 3) Hasil membuktikan bahwa diantara Komitmen Organisasi, Budaya Organisasi dan Motivasi, Variabel Motivasi memiliki pengaruh yang paling signifikan terhadap Kinerja Karyawan di PT. Hantar Hamparan Hasil.
\end{abstract}

Kata kunci : Komitmen Organisasi, Budaya Organisasi dan Motivasi.

\section{Abstract}

The purpose of this study was to determine the factors that influence the performance of employees at PT. Introduce Results Overlay which includes Organizational Commitment (X1) Organizational Culture (X2) and Work Motivation (X3). This study uses a quantitative method sample 60 employees at PT. Deliver Overlay Results as respondents. Data collection is done using questionnaires. The data were analyzed using statistical, namely by using multiple regression analysis, the processing of which was carried out with the SPSS version 25.0 program. 1) The results of the analysis prove that the Organizational Commitment, Organizational Culture and Motivation variables simultaneously affect the performance of employees at PT. Deliver Results Overlays. 2) The results of the analysis prove that Organizational Commitment and Motivation have a partial effect on Employee Performance, while Organizational Culture has no partial effect on Employee Performance. 3 ) Result prove that between Organizational Commitment, Organizational Culture and Motivation, Motivation variables have the most significant influence on Employee Performance at PT. Deliver Results Overlays.

Keywords : Organizational Commitment, Organizational Culture and Motivation. 


\section{Pendahuluan}

Karyawan atau sumber daya manusia (SDM) dalam perspektif manajemen modern merupakan aset yang penting bagi perusahaan dan setiap perusahaan yang ingin berkembang wajib untuk memperhatikan faktor sumber daya manusia yang dimilikinya. Karena sumber daya manusia memiliki peranan dan fungsi yang sangat penting untuk tercapainya tujuan dan targat perusahaan. Sumber daya manusia di sini yaitu mencakup keseluruhan manusia yang berada di dalam organisasi seperti mereka yang terlibat dalam semua kegiatan operasional perusahaan mulai dari tingkatan level yang paling bawah sampai ke level yang berada paling atas (top management), meskipun berbeda-beda level, semua elemen sumber daya manusia tersebut memiliki peranan yang sama dalam tercapai tidaknya tujuan perusahaan, pengabadian terhadap salah satu bagian mengakibatkan terhambatnya pencapaian tujuan perusahaan. Berhasil tidaknya perusahaan untuk mencapai tujuan yang telah ditetapkan sebelumnya sangatlah bergantung pada kemampuan - kemampuan sumber daya manusia atau karyawan yang berada didalam perusahaan tersebut.

Menurut Handoko dkk, komitmen organisasi adalah tingkatan dimana seseorang mempunyai kemauan tinggi untuk mewujudkan tujuan - tujuan organisasi dan memelihara kesejahteraan keanggotaan di dalam organisasi. Anggota organisasi yang berkomitmen terhadap organisasinya akan mengembangkan pola pandang yang lebih positif terhadap organisasi dan dengan senang hati akan mengeluarkan energi ekstra demi kepentingan organisasi.

Budaya organisasi mempunyai peran penting dalam menentukan pertumbuhan organisasi. Organisasi dapat tumbuh dan berkembang karena budaya organisasi yang terdapat didalamnya mampu merangsang semangat kerja sumber daya manusia anggotanya, sehingga kinerja organisasi meningkat. Budaya organisasi adalah cara orang melakukan sesuatu dalam organisasi, merupakan satuan norma yang terdiri atas keyakinan, sikap, core values dan pola perilaku yang dilakukan orang dalam organisasi. Menurut Robbins dan Judge, salah satu hasil yang spesifik dari budaya organisasi yang kuat adalah menurunnya tingkat perputaran karyawan. Keharmonisan tujuan yang tercapai antara karyawan dan organisasi melalui budaya akan membangun suatu komitmen organisasional dalam 
diri karyawan.

Kinerja tidaklah mungkin mencapai hasil yang maksimal apabila tanpa adanya motivasi, karena motivasi merupakan suatu kebutuhan di dalam usaha untuk mencapai tujuan organisasi. Begitu juga berbagai ragam kemampuan pegawai akan sangat berpengaruh terhadap kinerja mengingat pegawai merupakan titik sentral dalam melaksanakan tugas pokok dan fungsinya. Motivasi adalah faktor-faktor yang ada dalam diri seseorang yang menggerakkan dan mengarahkan perilakunya untuk memenuhi tujuan-tujuan tertentu. Sedangkan menurut Sutrisno, motivasi ialah salah satu faktor pendorong seseorang melakukan segala aktivitas organisasi yang bertujuan untuk kemajuan organisasi itu sendiri.

Motivasi merupakan suatu dorongan kepada seluruh karyawan sehingga diharapkan mereka mampu bekerja dengan lebih baik sesuai dengan potensi yang mereka miliki. Dengan adanya motivasi yang melibatkan mereka dalam semua kegiatan organisasi diharapkan mampu untuk menyelesaikan semua permasalahan yang harus diselesaikan pada setiap individu pekerja dengan lebih optimal sehingga dapat meningkatkan kinerjanya. Pemberian motivasi sangat penting karena menurut Hasibuan menjelaskan bahwa motivasi kerja adalah pemberian daya penggerak yang menciptakan kegairahan kerja seseorang agar mereka mau bekerja sama, bekerja efektif, dan terintegrasi dengan segala daya upaya untuk mencapai tujuan organisasi.

Namun pada kenyataannya budaya organisasi masih kurang bagus diterapkan oleh karyawan, komitmen yang sudah dibuat oleh perusahaan masih sering dilanggar. Hal tersebut dapat terlihat pada keterlambatan masuk karyawan yang dalam peraturan perusahaan masuk kerja jam 08:00 tapi masih ada juga karyawan yang masuk jam 08:30 dan masih terjadinya pelanggaran disiplin absensi dari karyawan. Serta dari pihak manajemen mengeluhkan tentang karyawan yang semakin menurun. Selain itu perusahaan berusaha untuk memperbaiki budaya organisasi dengan membudayakan budaya saling kerja sama antar bagian untuk meningkatkan keharmonisan dan kekompakan dalam bekerja. Motivasi yang dibrikan oleh pimpinan sudah bagus namun masih saja karyawan sedikit tidak menghiraukan, banyak melakukan pelangaran - pelangaran kecil pada jam - jam kerja juga. 


\section{Metode Penelitian}

Dalam penelitian ini pendekatan yang digunakan adalah pendekatan kuantitatif, yaitu penelitian yang analisis datanya sangat dipengaruhi oleh variabel variabel yang dianalisis. Penelitian ini dilakukan pada karyawan PT. Hantar Hamparan Hasil di Pasuruan.

Populasi yang digunakan dalam penelitian ini adalah karyawan PT. Hantar Hamparan Hasil di yang berjumlah 150 orang. Selanjutnya dalam menetapkan besarnya sampel (sample size) dalam penelitian ini didasarkan pada perhitungan yang dikemukakan oleh Slovin [6], dengan demikian maka diperoleh jumlah pada penelitian ini yaitu 60 responden.

Teknik pengambilan sampel Dalam penelitian ini menggunakan probability sampling dan teknik sampel yang digunakan adalah simple random sampling karena pengambilan sampel dari populasi dilakukan secara acak tanpa memperhatikan status yang ada dalam populasi.

Jenis dan sumber data yang digunakan dalam penelitian ini adalah data primer dan data sekunder. Teknik pengumpulan data yang digunakan yaitu kuisioner, wawancara dan dokumenter. Teknik analisis data yang digunakan dalam penelitian ini yaitu regeresi linier berganda.

\section{Hasil Dan Pembahasan}

\section{Hasil Uji Validitas Dan Reliabilitas}

Berdasarkan pengujian yang dilakukan oleh peneliti, maka diperoleh hasil bahwa seluruh item pernyataan dari varibel komitmen organisasi, budaya organisasi, dan motivasi terhadap kinerja karyawan dinyatakan valid dengan nilai $r$ hitung $>r$ tabel $(0,250)$.

Sedangkan hasil uji reliabilitas dalam uji ini menunjukkan nilai cronbach's alpha dari variabel komitmen organisasi 0,641, budaya organisasi 0,611, motivasi 0,738, kinerja karyawan 0,711, maka nilai cronbach's alpha > 0,60. Jadi dapat disimpulkan bahwa kuisioner yang digunakan dalam penelitian ini memberikan konsistensi yang diberikan oleh responden. 


\section{Analisis Regresi Linier Berganda}

Tabel 1 Analisis Regresi Linier Berganda

\begin{tabular}{|c|c|c|c|c|c|}
\hline \multirow{3}{*}{ Model } & \multirow{2}{*}{\multicolumn{2}{|c|}{$\begin{array}{l}\text { Unstandardized } \\
\text { Coefficients }\end{array}$}} & \multicolumn{3}{|l|}{ Standardized } \\
\hline & & & Coefficients & $\mathrm{t}$ & Sig. \\
\hline & $\mathrm{B}$ & Std. Error & Beta & & \\
\hline (Constant) & , 278 & 1,124 & & ,248 & ,805 \\
\hline $\begin{array}{l}\text { KomitmenOrganisa } \\
1 \mathrm{si}\end{array}$ & , 194 & ,092 & 151 & 2,114 & ,039 \\
\hline BudayaOrganisasi & ,029 & ,085 & ,037 & ,343 & ,733 \\
\hline Motivasi & 636 & 099 & ,782 & 6,402 & ,000 \\
\hline
\end{tabular}

Sumber : Data dari hasil pengolahan SPSS

Berdasarkan hasil uji regresi linier berganda pada tabel diatas, dapat diketahui persamaan regresi yang diperoleh adalah sebagai berikut:

$Y=a+b_{1} X_{1}+b_{2} X_{2}+b_{3} X_{3}$

$Y=0.278+0.194+0.029+0.636$

Berdasarkan rumusan regresi di atas dapat di artikan sebagai berikut :

a. Nilai konstanta sebesar 0.278 , berarti bahwa jika tidak ada 3 variabel bebas maka variabel kinerja karyawan sebesar 0.278 .

b. Nilai koefisien dari komitmen organisasi ( $\left.\mathrm{X}_{1}\right)$ sebesar 0.194 , berarti bahwa setiap kenaikan satuan variabel komitmen organisasi ( $X_{1}$ ) akan menaikkan variabel kinerja karyawan (Y) sebesar 0.194.

c. Nilai koefisien dari budaya organisasi ( $\mathrm{X}_{2}$ ) sebesar 0.029 , berarti bahwa setiap kenaikan satuan variabel budaya organisasi ( $\left.\mathrm{X}_{2}\right)$ akan menaikkan variabel kinerja karyawan (Y) sebesar 0.029.

d. Nilai koefisien dari motivasi ( $\mathrm{X}_{3}$ ) sebesar 0.636, berarti bahwa setiap kenaikan satuan variabel motivasi ( $\mathrm{X}_{3}$ ) akan menaikkan variabel kinerja karyawan (Y) sebesar 0.636. 


\section{Uji F (Simultan)}

\section{Tabel 2 Hasil Uji Simultan}

ANOVA ${ }^{\mathrm{a}}$

\begin{tabular}{|c|c|c|c|c|c|}
\hline \multicolumn{2}{|c|}{ Model } & $\begin{array}{l}\text { Sum } \\
\text { Squares }\end{array}$ & of $\mathrm{df}$ & $\begin{array}{l}\text { Mean } \\
\text { Square }\end{array}$ & Sig. \\
\hline \multirow{3}{*}{1} & $\begin{array}{l}\text { Regressio } \\
\mathrm{n}\end{array}$ & 277,860 & 3 & 92,620 & \multirow[t]{3}{*}{$126,280,000^{b}$} \\
\hline & Residual & 41,073 & 56 & ,733 & \\
\hline & Total & 318,933 & 59 & & \\
\hline
\end{tabular}

a. Dependent Variable: Kinerja

b. Predictors: (Constant), Motivasi, KomitmenOrganisasi, BudayaOrganisasi

Sumber : Data dari hasil pengolahan SPSS

Dari tabel 2 menunjukkan bahwa terdapat pengaruh secara simultan atau secara bersama - sama dari ketiga variabel yaitu variabel komitmen organisasi $\left(\mathrm{X}_{1}\right)$, budaya organisasi $\left(\mathrm{X}_{2}\right)$, motivasi $\left(\mathrm{X}_{3}\right)$ terhadap kinerja karyawan $(\mathrm{Y})$. Adapun pengujian uji $\mathrm{F}$ sebagai berikut: dengan df $1=\mathrm{k}-1=3$ dan df $2=\mathrm{n}-\mathrm{k}$ $=60-4=56$ sehingga di peroleh $\mathrm{F}$ tabel sebesar 2.770. Sesuai dengan hasil perhitungan Uji F yang dilakukan, diperoleh nilai $F$ hitung sebesar 126,280. Sehingga nilai $F$ hitung ini lebih besar dari nilai $F$ tabel yaitu sebesar 2,770 . Nilai signifikansi yang diperoleh adalah sebesar 0,000 , jadi nilai signifikansi ini lebih kecil dari nilai $\alpha$ nilai yaitu 0,05. Karena ( $\left.F_{\text {hitung }}>F_{\text {tabel }}=126.280>2,770\right)$ dan ( $\operatorname{sig}<\alpha=0,000<0,005$ ) maka Ho ditolak dan Ha diterima. Artinya komitmen organisasi, budaya organisasi dan motivasi berpengaruh secara simultan terhadap kinerja karyawan di PT. Hantar Hamparan Hasil. Hal ini menyatakankan bahwa komitmen organisasi di dalam perusahaan tersebut sudah baik, hal tersebut dapat dilihat dari perolehan tanggapan responden yang ada di dalam kuesioner komitmen organisasi. Jawaban yang paling dominan terhadap pernyataan bahwa karyawan memiliki perasaan sebagai pegawai yang baik dan mempunyai kesempatan bekerja secara tetap, serta karyawan juga merasa sudah bertanggung jawab terhadap tugas - tugas organisasi.

Penelitian ini didukung oleh teori Khan et al yang mengatakan bahwa 
komitmen dari seorang karyawan terhadap organisasinya dapat menjadi instrumen penting untuk meningkatkan kinerja dari karyawan tersebut. Hal ini sejalan dengan penelitian terdahulu, yang membuktikan bahwa variabel motivasi dan komitmen organisasi berpengaruh positif secara simultan terhadap kinerja karyawan.

\section{Uji t ( Parsial)}

\section{Tabel 3 Hasil Uji Parsial}

\begin{tabular}{|c|c|c|c|c|c|c|}
\hline \multicolumn{2}{|c|}{ Model } & \multicolumn{2}{|c|}{$\begin{array}{l}\text { Unstandardized } \\
\text { Coefficients }\end{array}$} & \multirow{2}{*}{$\begin{array}{l}\text { Standardize } \\
\text { d } \\
\text { Coefficients } \\
\text { Beta }\end{array}$} & \multirow[t]{2}{*}{$\mathrm{t}$} & \multirow[t]{2}{*}{ Sig. } \\
\hline & & $\overline{\mathrm{B}}$ & Std. Error & & & \\
\hline \multirow{4}{*}{1} & (Constant) & ,278 & 1,124 & & ,248 & ,805 \\
\hline & $\begin{array}{l}\text { KomitmenOrganisa } \\
\text { si }\end{array}$ & ,194 & ,092 & 151 & 2,114 & 039 \\
\hline & BudayaOrganisasi & ,029 & ,085 & ,037 & ,343 & ,733 \\
\hline & Motivasi &, 636 & ,099 & 782 & 6,402 & ,000 \\
\hline
\end{tabular}

Sumber: Data dari hasil pengolahan SPSS

Dari tabel diatas menunjukkan bahwa $\mathrm{t}$ tabel dilihat dari tabel dengan nilai $\mathrm{df}=\mathrm{n}-\mathrm{k}=60-4=56$ sehingga $\mathrm{T}$ tabel diperoleh sebesar 1.672. Tabel di atas menjelaskan uji hipotesis secara parsial atau individu adalah sebagai berikut :

a) Variabel Komitmen Organisasi (X

Diketahui nilai ( $\mathrm{t}$ hitung $>\mathrm{t}$ tabel $=2,114>1.672$ ) dan $(\operatorname{sig}<\alpha=$ $0,039<0,05)$ maka Ho ditolak dan Ha diterima, artinya variabel independen yaitu komitmen organisasi ( $\left.\mathrm{X}_{1}\right)$ berpengaruh secara parsial terhadap variabel dependen yaitu kinerja (Y). Hal ini menyatakankan bahwa komitmen organisasi di dalam perusahaan tersebut sudah baik, dapat dilihat dari perolehan tanggapan responden yang ada di dalam kuesioner komitmen organisasi. Jawaban yang paling dominan terhadap pernyataan bahwa karyawan merasa sudah bertanggung jawab terhadap tugas - tugas organisasi dan mempunyai kesempatan bekerja secara tetap serta karyawan memiliki perasaan sebagai pegawai yang baik.

Penelitian ini didukung oleh teori dari Sopiah yang menyatakan bahwa komitmen organisasi merupakan suatu ikatan secara psikologis 
yang terjadi pada diri seseorang terhadap organisasi sehingga orang yang berkomitmen tersebut memiliki kemauan untuk mempertahankan kedudukan organisasi, memiliki kemauan yang tinggi untuk memajukan organisasi dan memiliki loyalitas yang tinggi untuk tidak meninggalkan oranisasi dalam keadaan apapun.

b) Variabel Budaya Organisasi $\left(\mathrm{X}_{2}\right)$

Diketahui nilai ( $\mathrm{t}$ hitung $<\mathrm{t}$ tabel $=0,343<1.672$ ) dan (sig $>\alpha=$ 0,733 > 0,05) maka Ho diterima dan Ha ditolak, artinya variabel independen yaitu budaya organisasi $\left(\mathrm{X}_{2}\right)$ tidak berpengaruh signifikan secara parsial terhadap variabel dependen yaitu kinerja (Y). Maka dapat disimpulkan bahwa baik dan tidaknya budaya yang ada di dalam organisasi tersebut akan menghasilkan pengaruh yang tidak banyak atau dapat dikatakan pengaruhnya kecil terhadap kinerja dari para karyawan. Hasil penelitian terdahulu dengan yang sekarang tidak sejalan karena budaya dalam satu organisasi dengan organisasi yang lain tidaklah sama, begitupun dengan para anggota organisasinya tidak sama sehingga menghasilkan jawaban kuesioner yang berbeda antara anggota organisasi satu dengan yang lainya

c) Variabel Motivasi $\left(\mathrm{X}_{3}\right)$

Diketahui nilai ( $\mathrm{t}$ hitung $>\mathrm{t}$ tabel $=6,402>1,672)$ dan $(\operatorname{sig}<\alpha=$ $0,00<0,05)$ maka Ho ditolak dan Ha diterima, artinya variabel independen yaitu motivasi (X3) berpengaruh secara parsial terhadap variabel dependen yaitu kinerja (Y). hal tersebut dapat dilihat dari tanggapan responden terhadap pernyataan yang mengatakan bahwa karyawan merasa diterima oleh organisasi dan karyawan selalu berusaha meningkatkan kemampuan dan potensi optimal untuk mencapai prestasi kerja.

Penelitian ini didukung oleh teori dari Ghozali yang menyatakan motivasi adalah pemberian dorongan - dorongan individu untuk bertindak yang menyebabkan orang tersebut berperilaku dengan cara tertntu yang mengarah pada tujuan. Pemberian motivasi merupakan salah satu tujuan agar karyawan yang diberi motivasi dapat bekerja sesuai dengan acuan kerja dan tanggung jawab yang diberikan sehingga tujuan perusahaan 
tercapai dengan baik.

\section{Koefisien Korelasi ( R )}

\section{Tabel 4 Hasil Analisis ( R ) dan $\left(R^{2}\right)$}

\begin{tabular}{lllll}
\hline Model & $\mathrm{R}$ & R Square & $\begin{array}{l}\text { Adjusted } \\
\text { Square }\end{array}$ & $\begin{array}{c}\text { R Std. Error of the } \\
\text { Estimate }\end{array}$ \\
\hline 1 &, $933^{\mathrm{a}}$ &, 871 &, 864 &, 85642 \\
\hline
\end{tabular}

Sumber: Data dari hasil pengolahan SPSS

Dari tabel 4 diatas menunjukkan bahwa nilai koefisien korelasi berganda pada penelitian ini sebesar 0.933 atau mendekati 1, sehingga terdapat hubungan yang kuat dan searah antara variabel bebas yang meliputi variabel komitmen organisasi $\left(X_{1}\right)$, budaya organisasi $\left(X_{2}\right)$, dan motivasi $\left(X_{3}\right)$ terhadap variabel terikat yaitu kinerja (Y). Dapat diartikan bahwa jika ketiga variabel bebas (X) ditingkatkan maka variabel terikat (Y) juga akan meningkat, demikian pula sebaliknya.

\section{Koefisien Determinasi $\left(\mathbf{R}^{2}\right)$}

Dari tabel 4 menunjukkan bahwa koefisien determinan pada penelitian ini sebesar 0.871 atau $87.1 \%$, sehingga variabel komitmen organisasi ( $\left.\mathrm{X}_{1}\right)$, budaya organisasi $\left(\mathrm{X}_{2}\right)$, dan motivasi $\left(\mathrm{X}_{3}\right)$ dapat menjelaskan kinerja karyawan dan sisanya $12.9 \%$ dijelaskan oleh variabel lain.

\section{Kesimpulan dan Saran}

\section{Kesimpulan}

Berdasarkan hasil analisis dan pengujian diatas, maka dapat disimpulkan sebagai berikut :

a. Komitmen organisasi, budaya organisasi, dan motivasi berpengaruh secara simultan terhadap kinerja karyawan.

b. Komitmen organisasi, dan motivasi berpengaruh secara parsial terhadap kinerja karyawan, sedangkan budaya organisasi tidak berpengaruh secara parsial terhadap kinerja karyawan.

c. Diantara komitmen organisasi, budaya organisasi, dan motivasi, variabel motivasi memiliki pengaruh yang paling signifikan terhadap kinerja karyawan. 
Saran

Berdasarkan hasil kesimpulan yang telah diuraikan maka saran yang bisa diberikan oleh penulis, yaitu :

a. Hendaknya manajemen PT. Hantar Hamparan Hasil memperhatikan masalah mengenai komitmen organisasi karena bedasarkan hasil penelitian menunjukkan bahwa komitmen organisasi memiliki pengaruh terhadap kinerja karyawan. Dengan adanya komitmen organisasi yang baik akan dapat membuat kinerja karyawan yang lebih baik.

b. Hendaknya manajemen PT. Hantar Hamparan Hasil memperhatikan masalah mengenai budaya organisasi karena bedasarkan hasil penelitian menunjukkan bahwa budaya organisasi memiliki pengaruh secara simultan terhadap kinerja karyawan. Dengan adanya budaya organisasi yang baik akan dapat membuat kinerja karyawan yang lebih baik.

c. Hendaknya manajemen PT. Hantar Hamparan Hasil memperhatikan masalah mengenai motivasi karena bedasarkan hasil penelitian menunjukkan bahwa motivasi memiliki pengaruh terhadap kinerja karyawan. Dengan adanya motivasi yang baik akan dapat membuat kinerja karyawan yang lebih baik.

d. Bagi peneliti yang selanjutnya sebaiknya melakukan perkembangan penelitian ini dengan menambah variabel lain karena masih banyak faktor yang mempengaruhi kinerja karyawan, sehingga dapat menambah kontribusi dan pengetahuan di masa yang akan datang.

\section{Daftar Pustaka}

Kurniawan, Donny, and Yuniati Tri. 2017. "Pengaruh Budaya Organisasi, Motivasi Kerja Dan Kompensasi Terhadap Kinerja Karyawan.” Jurnal Ilmu Dan Riset Manajemen 6 (7): 1-18.

Melizawati. 2015. "Pengaruh Komitmen Organisasi Terhadap Kinerja Karyawan (Studi Kasus Pada PT. Indotirta Abadi Di Gempol Pasuruan)," 1-17.

Murty, Windy Aprilia dan Hudiwinarsih, Gunasti. 2012. "Pengaruh Kompensasi dan Komitmen Organisasional Terhadap Kinerja Karyawan Bagian Akuntansi (Studi Kasus Pada Perusahaan Manufaktur di Surabaya). The Indonesian Accounting Review Volume 2, No. 2, July 2012, pages 215 - 228

Purnamasari Rita, and MBA Mardalis Ahmad, SE. 2016. "Pengaruh Budaya Organisasi, Motivasi dan Komitmen Organisasi Terhadap Kinrja Karyawan CV. Mustika Sragen."

Putra, Siswanto Wijaya. 2015. "Pengaruh Komitmen Organisasi, Budaya Organisasi, Gaya Kepemimpinan Dan Lingkungan Terhadap Kinerja Karyawan Pada Industri Kecil." Jurnal

Ekonomi

Modernisasi

11

(1):

62-77. 
http://ejournal.unikama.ac.id/index.php/JEKO/article/view/869.

Sugiyono. 2014. Metode Penelitian Bisnis (Pendekatan Kuantitatif Kualitatif Dan R\&D). Bandung: Alfabeta.

Triningtyas, Wahyu Yastuti. 2014. "Pengaruh Motivasi Kerja, Pelatihan dan Komitmen Organisasi Terhdap Kinerja Karyawan di Pabrik Gula Tulanggan Sidoarjo." 